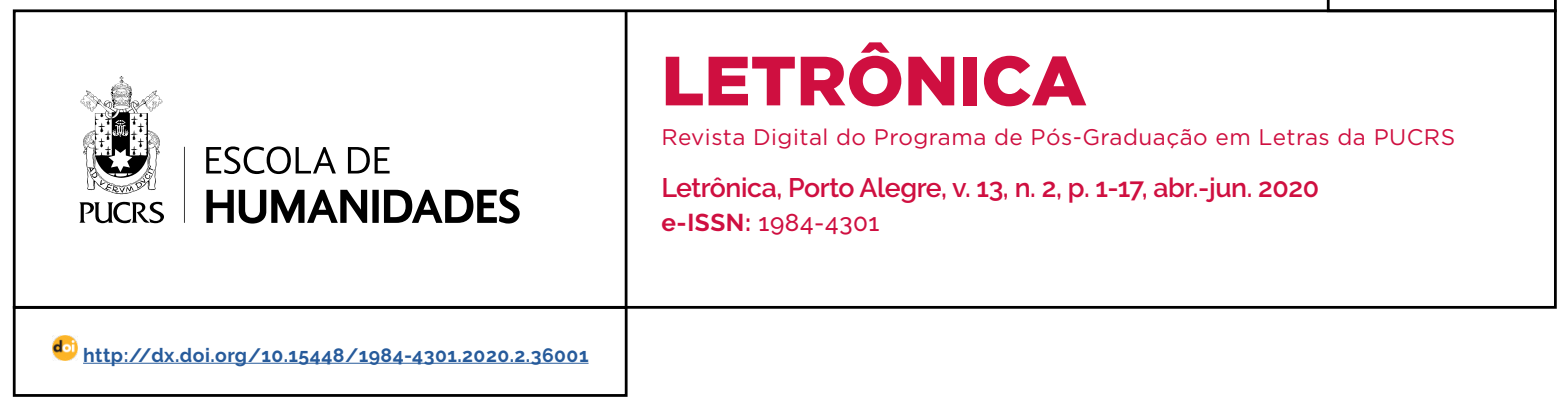

\title{
“Comunicação não-violenta" pelas lentes da Linguística: embates no combate à intolerância
}

\author{
"Nonviolent communication" through the lens of Linguistics. \\ clashes in the fight against intolerance
}

\author{
Ana Raquel Motta ${ }^{1}$ \\ orcid.org/0000-0003-3800-8326 \\ anaraquelms@gmail.com
}

Recebido em: 15 out. 2019

Aprovado em: 17 dez. 2019

Publicado em: 13 ago. 2020

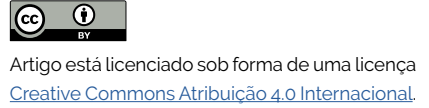

Creative Commons Atribuição 4.0 Internacional.
Resumo: O presente artigo visa a analisar e discutir a proposta conhecida como "Comunicação não-violenta" (CNV) através das lentes da Linguística. Tal proposta tem sido utilizada em muitos países do mundo como ferramenta no combate ao discurso intolerante, mas é pouco conhecida, ou até desprezada, nos meios acadêmicos dos Estudos da Linguagem. Este artigo analisa os quatro componentes da CNV: "fato/observação", "sentimento", "necessidade" e "pedido", de acordo com o postulado em Rosenberg $(2006,2019)$. As conclusões são que a contribuição teórica da Linguística, especialmente de conceitos como "discurso", "simulacro", "evidencialidade", "princípio da cooperação conversacional", entre outros, proporciona mais clareza e coerência para noções utilizadas sem rigor teórico pela CNV e podem, por isso, contribuir para o desenvolvimento da proposta. Em relação à Linguística, espera-se que o artigo contribua para que a disciplina esteja mais engajada na construção de um mundo menos violento, seja analisando propostas já existentes de linguagem para a paz, como o que se faz aqui, seja propondo novas abordagens.

Palavras-chave: Linguagem para a paz. Cultura de paz. Discurso intolerante.

Abstract: This article aims to analyze and discuss the proposal known as "Nonviolent Communication" (NVC) through the lens of Linguistics. Such proposal has been used in many countries of the world as a tool in the fight against intolerant discourse, but it is little known, or even neglected, in the academic circles of language studies. This article analyzes the four components of NVC: "fact/observation", "feeling", "need" and "request" according to the postulate in Rosenberg (2006; 2019). The conclusions are that the theoretical contribution of Linguistics, especially concepts such as "discourse", "simulacrum", "evidentiality", "principle of conversational cooperation", among others, provides more clarity and coherence for notions used without theoretical rigor by NVC and can therefore contribute to the development of the proposal. Regarding Linguistics, it is hoped that the article will contribute to making the discipline more engaged in building a less violent world, either by analyzing existing language proposals for peace, such as what is being done here, or by proposing new approaches.

Keywords: Language for peace. Culture of peace. Intolerant speech.

\section{Introdução}

O discurso intolerante é aquele que tem dificuldade de aceitar a existência do outro: de outro ponto de vista, outros pensamentos, outros modos de viver. Por conta de um recrudescimento desse tipo de discurso (ou por estar mais frequente na contemporaneidade ou por tomar dimensões e causar estragos maiores, devido a novas formas de circulação), diferentes atores sociais se voltam à questão, a fim de analisála, compreendê-la e, se for o caso, propor meios para enfrentá-la. É o 
que tem se dado com a Linguística e a Linguística Aplicada², em que temas como "polêmica" (p. ex. AMOSSY, 2017), "moral" (p. ex. PAVEAU, 2015) e os direitos humanos no geral (p. ex. SILVA; PALMA, 2018) têm se tornado mais frequentes.

No entanto, chama a atenção o quanto a discussão no universo acadêmico se conserva ainda distante dos debates, práticas e propostas dos diversos movimentos sociais que lidam diariamente com questões de intolerância e dificuldades de convívio entre grupos sociais e mesmo entre pessoas. A diminuição dessa decalagem é ao que o presente artigo se propõe. Assim, a partir do campo acadêmico da Linguística, analisarei uma proposta de combate à intolerância eà violência que, apesar de presente em 65 paises do mundo como instituição oficial e praticada por milhares de ativistas sociais, educadores, políticos, advogados, juizes, entre outros, tem sido ignorada ou encarada com desdém por esta área de conhecimento. Trata-se da Comunicação nãoviolenta (doravante CNV), proposta inicialmente pelo psicólogo de base humanista Marshall Rosenberg, a partir de suas experiências em seu pais natal (Estados Unidos) com comunidades em conflitos étnicos e sociais e também em diversos paises do mundo com sociedades em guerra (por exemplo, conflito israelo-palestino, guerra civil iugoslava, entre outros).

Por tratar-se de uma proposta de educação para a paz ${ }^{3}$ através de mudanças na comunicação, como o nome indica, torna-se muito relevante que se compreenda o que está sendo entendido por "comunicação", "língua" e "linguagem", principalmente por a CNV não ter em suas bases reflexões linguísticas e, aliás, contar com bem pouca reflexão teórico-acadêmica de qualquer campo. Assim, o presente artigo é uma contribuição da Linguística através de apontamentos de possiveis (in)compatibilidades entre a CNV e a grande área da Linguagem. Concordando com Evensen4 (1998, p. 81), "se indagarmos que tipo de conhecimento é buscado na Linguística Aplicada, teremos que considerar [...] que abrangeria entender, explicar ou solucionar problemas e aprimorar soluções existentes".

A CNV é, sem dúvida, uma solução existente que vem sendo, desde a década de 1960, utilizada para combater o discurso intolerante. O que os Estudos da Linguagem têm a dizer sobre ela? Ressalto que não se trata, aqui, de cobrar da CNV o que ela não se dispõe a dar, tampouco cobrar da Linguística o que ela não se dispõe a dar. O objetivo deste artigo é, respeitando as características das duas áreas, examinar a CNV com o olhar da Linguística, a fim de fomentar uma dupla contribuição. Para os pesquisadores que, como formadores de professores de línguas que é o meu caso - ou, de alguma outra forma, também interessados em como as pesquisas acadêmicas podem participar mais ativamente da construção de um mundo mais justo, humanitário, tolerante e pacífico, a proposta da CNV é capaz de questionar certezas teóricas com experiências práticas e a partir de um fértil olhar externo. Para os praticantes, estudiosos e entusiastas da CNV, os conceitos da Linguística podem proporcionar mais coerência e firmeza a afirmações que, na condição em que se encontram hoje, por vezes beiram o "achismo" e afastam da abordagem uma pesquisa acadêmica mais estabelecida.

o corpus escolhido para análise é a bibliografia mais básica da CNV, os dois principais livros de seu fundador Marshall Rosenberg: Comunicação nãoviolenta: técnicas para aprimorar relacionamentos pessoais e profissionais (2006) e A linguagem da paz em um mundo de conflitos (2019). Por condensar os princípios da CNV e ser a obra base de todo o desenvolvimento posterior (que vem ocorrendo muito mais como prática do que como teoria), o primeiro livro já poderia ser material suficiente para os objetivos deste artigo. No entanto, considero que o segundo (embora em muitos aspectos repita e ilustre o primeiro) apresenta uma ênfase

\footnotetext{
2 Neste artigo, o foco será principalmente a Linguística, embora, por vezes, eu mencione a grande área da Linguagem ou os Estudos da Linguagem de um modo geral.

3 Educação para paz é como têm sido chamadas iniciativas educacionais que visam a promover a cultura de paz, nos moldes preconizados pela UNESCO em sua assembleia geral de 1999, ocasião em que a década seguinte (2000 a 2010) foi escolhida como década da cultura de paz. Para a Unesco, "cultura de paz" é um conjunto de estilos de vida, comportamentos, tradições, valores e atitudes baseados na prática da não-violência.

4 Embora Evensen se refira à Linguística Aplicada, acredito que sua asserção nesta citação possa ser estendida à Linguística.
} 
na dimensão sistêmica (social e política) da CNV, que fica um pouco apagada no primeiro.

Após esta breve introdução, a seção um aborda a questão da violência na linguagem. Na seção dois, apresento a CNV com um histórico panorâmico de sua constituição e circulação. A seção três concentra a análise propriamente dita, e suas quatro subseções examinam os quatro componentes da CNV - fato/observação, sentimento, necessidade, pedido - utilizando para tal reflexões relacionadas, mais ou menos diretamente, à grande área da Linguagem. Ao fim, apresento as considerações finais a que este artigo conseguiu chegar, no intuito de contribuir tanto para o aprimoramento da CNV quanto para uma maior abertura dos pesquisadores da linguagem frente às práticas sociais que abordam a comunicação, para além da pesquisa universitária.

\section{A violência na linguagem}

Perelman e Olbrechts-Tyteca (1996), em seu clássico Tratado da Argumentação, lançado em 1958, já comemoram o fato de as controvérsias e batalhas verbais terem, em grande parte, substituido a violência física em muitos locais do mundo. Assim, afirmam que

o uso da argumentação implica que se tenha renunciado a recorrer unicamente à força, que se dê apreço à adesão do interlocutor, obtida graças a uma persuasão racional, que este não seja tratado como um objeto, mas que se apele à sua liberdade de juizo (PERELMAN; OLBRECHTS-TYTECA, 1996, p. 61).

Ao inaugurarem a "nova retórica", esses autores pretendiam justamente reabilitar um campo de estudos e pesquisar sua racionalidade, que não coincide com a racionalidade do ideal cartesiano. Tratava-se de um elogio aos mecanismos de argumentação - para fazer aderir a teses e/ ou persuadir a ações - área que havia ficado desacreditada pela Filosofia e pelo Direito por tratar do "verossímil" e não do "verídico". Partindo do princípio de que, em língua natural, não há demonstração pura, sem interferência das subjetividades, Perelman e Olbrechts-Tyteca desfizeram a distinção que considerava a lógica como clarificadora de evidências e a retórica como falsificadora, por buscar "apenas" o verossimil, e não o verdadeiro. Essa distinção será importante neste artigo.

Alguns movimentos sociais, após a década de 1950, também celebraram as linguagens verbal, corporal, musical, visual - como capazes de substituir a violência física e atuar como meio mais eficaz para luta por direitos e pela paz. $O$ movimento Hip Hop, por exemplo, nascido nos Estados Unidos no final da década de 1960, mobilizava os jovens negros das periferias para que colocassem nas palavras do rap, na dança do break, na arte visual do grafite, nas bases sonoras do $D J$ as reivindicações da comunidade. ${ }^{5}$

Vista pelo viés da capacidade humana de convencer e persuadir, a palavra seria, portanto, uma aliada de nossa espécie para se distanciar da violência. No entanto, o que acarreta, na contemporaneidade, uma preocupação constante e crescente com o discurso violento? Podemos aventar três hipóteses, não excludentes: i) a violência física continua, e ela quase sempre vem acompanhada de ou precedida por violência verbal; ii) a palavra violenta, devido à era da indução algoritmica em que vivemos, ganha poderes de se alastrar e amplificar, destruindo reputações e até vidas; iii) após termos chegado a um consenso - ao menos teórico - de que a violência física deve ser erradicada, temos condições de pensar na violência verbal e de combatê-la também. Passemos a analisar essas três hipóteses.

Quanto à primeira, embora, como espécie, já saibamos argumentar há alguns milênios ${ }^{6}$. infelizmente estamos ainda longe de erradicar a violência física, de humanos contra humanos,? do planeta. Não é necessário buscar muito para encontrar, em níveis macro ou micro, exemplos contemporâneos de guerras, atentados terroristas,

\footnotetext{
5 Para um histórico do movimento Hip Hop, ver Silva (1998), Tella (2000) e Rocha, Domenich e Casseano (2001).

Alguns autores, como Koch (2000), defendem que a argumentação é a função primordial da linguagem humana. De fato, é dificil imaginar linguagem sem argumentação, e podemos identificá-la desde manifestações precoces do desenvolvimento infantil (Cf. PEREIRA DE CASTRO, 1985; BANKS-LEITE, 1996).

7 Não abordarei, neste artigo, a violência do ser humano contra os outros animais ou contra o meio ambiente, embora associações bastante relevantes e profundas sejam possiveis.
} 
massacres, chacinas, agressões físicas entre grupos, assassinatos, estupros, brigas que causam ferimentos leves ou graves. Infelizmente, a violência em nosso mundo movimenta muito dinheiro e mobiliza muitos esforços e inteligências para continuar sendo planejada e executada, muitas vezes como programa político, conforme alerta Galtung (2018).

Para o que propõe este artigo, é importante ressaltar que a violência verbal está presente em praticamente todos os atos de violência física, seja através de insultos, gritos ou humilhação. Nas escolas brasileiras, por exemplo, o estudo da UNESCO Violências nas escolas (ABRAMOVAY; RUA, 2002), através de amplo mapeamento, afirma, como parte de suas conclusões, que é difícil traçar um limite entre a violência verbal e física:

O mais comum nas escolas parece ser situações-limite entre ameaças e brigas, os bate-bocas e discussões. Há casos em que mesmo começando com troca de ameaças, desaforos, ofensas ou provocações, chegam a um ponto em que a escola não consegue controlar. As brigas são consideradas como acontecimentos corriqueiros, sugerindo a banalização da violência e, pela sua legitimação, como mecanismos de resolução de conflitos (ABRAMOVAY; RUA, 2002, p. 296).

Os casos de bullying ${ }^{8}$ na escola também comprovam a dificuldade de separar agressão verbal de agressão física.

Quanto à segunda hipótese, os meios contemporâneos de produção e circulação dos discursos, especialmente a grande presença da internet, têm criado novos gêneros discursivos e modificado o jogo de forças das interações linguageiras, muitas vezes de modo a favorecer a violência verbal. Amossy (2017, p. 169-172) elenca os sete parâmetros que indicam a violência em um enunciado: 1) há uma forte expressão ou coerção para impedir o outro de se exprimir; 2) o ponto de vista do outro é desconsiderado ou ridicularizado; 3) é utilizado o argumento ad hominem, ou seja, ataca-se a pessoa do adversário ao invés de sua tese; 4) assimila-se o outro ao Mal absoluto, demonizando-o; 5) a linguagem vem carregada de sentimentos fortes e agressivos; 6) insulta-se o adversário; e 7) há incitação de violência verbal e/ou física contra o adversário.

Essas sete características do discurso violento são, segundo a autora, insufladas pelo modo de circulação da internet, por exemplo, pelo uso de pseudônimos e avatares fictícios, que desresponsabilizam a pessoa por sua fala. São também estimuladas pela possibilidade de interagir violentamente com alguém despersonalizado, mas encarnado, ou seja, no espaço virtual, pode-se ter a sensação de atacar alguém que é real, mas a quem não se deve nenhuma obrigação de polidez, por ser desconhecido. Outra característica da rede mundial que tem o potencial de inflamar violentamente as interações verbais é a fraca formalidade de muitos espaços virtuais, em que opera fortemente o que Fairclough (1992) chama de "conversacionalização", em que o gênero conversação informal deixa fortes marcas em outras situações discursivas, mesclando o âmbito do público e o do privado.

Todas essas características podem ser reforçadas pelo uso de algoritmos, ou seja, pelo estudo de regularidades das práticas discursivas traçado por empresas de tecnologia a serviço de grupos econômicos ou políticos para definir nossos perfis e tendências de procedimentos e influenciar nossos gostos e comportamentos, desde o que compramos ou de quem somos amigos até em quem votamos e a que causas aderimos. A circulação de discursos na internet, cada vez menos livre, torna-se um terreno fértil para incitação da violência e da intolerância, através de notícias falsas e/ou manipuladas, reforço de visualizações apenas dentro da própria comunidade discursiva ou conteúdos selecionados a fim de incitar benevolência ou malevolência a setores sociais.

Finalmente, quanto à terceira hipótese, podemos defender, com Pinker (2011), que hoje provavelmente vivemos o período mais pacíico da história de nossa espécie. Tal postulação, embora pareça absurda especialmente em um país

8 Bullying é um tipo de agressão que ocorre entre pares, de maneira repetida, envolve agressor, praticante e testemunhas. O Grupo de Estudos e Pesquisas em Educação Moral (GEPEM), da Unesp e Unicamp, desenvolve um importante trabalho de pesquisa e combate à prática (Cf. SOUZA; TOGNETTA; LAPA; DE NADAI, 2018). 
muito violento, como o Brasil, está solidamente defendida pelo autor nas mais de 800 páginas de seu livro, abundantemente embasado em estudos de diferentes áreas. Ao menos do ponto de vista teórico, a violência física é vista pelo senso comum de nossa época como algo a ser erradicado.

Se assumirmos esse ponto de vista mais otimista, teria chegado o momento de, como humanidade, podermos combater a violência verbal, posto que hoje sabemos, pelos avanços da pedagogia e da psicologia, que ela pode ser bastante danosa para os sujeitos que a praticam e que a recebem. O combate à violência verbal também é uma conquista dos movimentos de defesa de minorias políticas, como crianças, mulheres, determinados grupos étnicos e/ou socioeconômicos.

Considerando, portanto, a validade das três hipóteses e articulando-as, podemos compreender que a violência verbal ganha contornos específicos e amplificados na contemporaneidade, e que combatê-la é parte importante da construção de uma sociedade mais justa, equânime e solidária.

\section{Comunicação não-violenta: uma proposta}

O processo de Comunicação não-violenta foi desenvolvido a partir da década de 1960 pelo psicólogo estadunidense Marshall Rosenberg e filia-se diretamente à resistência não-violenta, de Gandhi (1951)9. Começou como uma proposta prática, sendo concebida e desenvolvida por Rosenberg enquanto atuava como ativista pelos direitos civis na década de 1960 e em diversas escolas de educação pública em bairros violentos e segregados dos Estados Unidos. Ele também introduziu programas de paz em regiões em guerra como lugoslávia, Sérvia e Croácia, Burundi, Sri Lanka e Israel. O Centro de Comunicação nãoviolenta, fundado por ele, é hoje uma organização internacional presente em 65 paises.
Apenas após grande experiência prática, o autor publicou o livro Comunicação não-violenta, em 2003 nos Estados Unidos, traduzido no Brasil em 2006. A abordagem se baseia na premissa de que a maioria das culturas conhecidas educa para a violência através, por exemplo, de mecanismos de exploração dos semelhantes, recompensa ou punição - e que a linguagem tem papel preponderante nesta dinâmica. Para sair desse círculo vicioso, é preciso que reaprendamos a nos comunicar de maneira compassiva, de modo que "nossa compaixão natural floresça" (ROSENBERG, 2006, p. 21).

A CNV atua em três niveis: intrapessoal, interpessoal e sistêmico, e os três são necessários para a mudança do mundo no sentido de mais tolerância, compaixão, justiça e cuidado. A dimensão social e política (sistêmica), portanto, é elemento constitutivo que caminha conjuntamente à dimensão da transformação pessoal e das relações entre individuos. Entretanto, embora esteja no cerne da proposta inicial, a dimensão sistêmica muitas vezes é apagada e a CNV utilizada como uma técnica para contribuir para um funcionamento sem conflitos de estruturas autoritárias ou exploradoras, que Rosenberg (2019) denominaria como "gangues."10 O apagamento do aspecto sócio-político da CNV parece ocorrer por uma série de destacamentos, aforizações e retomadas. ${ }^{11}$

Sua técnica é, teoricamente, bastante simples, e pode ser resumida em quatro componentes: "1) observação; 2) sentimento; 3) necessidades; 4) pedido" (ROSENBERG, 2006, p. 25), descritas como:

[1] As ações concretas que estamos observando e que afetam nosso bem-estar;

[2] Como nos sentimos em relação ao que estamos observando;

[3] As necessidades, valores, desejos etc. que estão gerando nossos sentimentos;

\footnotetext{
9 Em uma evidente redução, escolhi o livro Non-violent resistance (Satyagraha) para representar aqui a filosofia de vida defendida por Mahatma Gandhi.

10 Dentre outras passagens sobre "gangues", lemos em Rosenberg (2019) o seguinte: "Ainda vivemos em uma sociedade de dominação, porém, substituímos o rei por uma oligarquia. No lugar de um individuo somos dominados por uma gangue. [...] Algumas se auto intitulam gangues de rua. Essas não são as que mais me assustam. [...] Outras gangues se autodenominam empresas multinacionais. Algumas se intitulam governos" (ROSENBERG, 2019, p. 118-119, grifo do autor).

11 Sobre "destacamentos", "aforizações" e "retomadas", ver Maingueneau (2010) e Motta (2009). Como exemplo, chama atenção a tradução do subtítulo do principal livro de Rosenberg, que, de Nonviolent communication: a language of life, passa a Comunicação não-violenta: técnicas para aprimorar relacionamentos pessoais e profissionais.
} 
[4] As ações concretas que pedimos para enriquecer nossa vida (ROSENBERG, 2006, p. 26, grifo do autor).

Apesar de sua utilização vir crescendo no Brasil e encontrar grande receptividade junto a diversos grupos sociais - como juizes e advogados (que a utilizam associada à justiça restaurativa e à mediação de conflitos), professores da Educação Básica (que a utilizam em sala de aula de todas as faixas etárias), educadores sociais (que a utilizam com diferentes grupos como facilitadora do convívio e da clarificação de objetivos e bandeiras comuns), profissionais de recursos humanos (que, em empresas públicas e privadas, a utilizam para melhoria das relações nos ambientes de trabalho) - a CNV enfrenta bastante descrédito e desconfiança nos meios acadêmicos.

Podemos relacionar essa pequena presença da CNV na academia brasileira à resistência para com todos os temas relacionados aos Direitos Humanos, que apenas há pouco tempo vêm aparecendo com maior frequência nas diferentes áreas de estudo universitário. ${ }^{12}$ Além de não serem temas tradicionais na maioria das áreas, o que, por si só, já pode significar resistências fortes, por desconfiança de que se trate de modismo ou inovações sem embasamento teórico, os Direitos Humanos costumam estar confinados às escolas de Direito. Também é preciso considerar uma tensão por vezes presente entre "ciência" e "militância". Estudar temas relativos aos Direitos Humanos implicaria defendê-los, o que, de acordo com uma visão estrita de pesquisa, poderia comprometer a "neutralidade da ciência".

Esses motivos gerais que dificultam o acolhimento dos temas relacionados aos Direitos Humanos na academia certamente têm seu papel quando pensamos na pequena acolhida da CNV nesses meios. No entanto, motivos mais especificos também contribuem - e acredito que com maior peso - para a presença quase nula da CNV nos trabalhos acadêmicos da área dos Estudos da
Linguagem. Esses motivos específicos precisam ser analisados, pois se devem à pouca compatibilidade de alguns pontos centrais da CNV em relação à Linguística como um todo e aos estudos de base enunciativa e discursiva de maneira mais forte.

\section{CNV pelas lentes da Linguística}

Como aspecto mais geral, sem entrar ainda na análise dos quatro componentes da CNV, cabe destacar a circulação desta abordagem no Brasil, que, como já dito, apresenta uma forte tendência a apagar ou diminuir o aspecto sistêmico e se concentrar nos aspectos intrapessoais e interpessoais do processo, contribuindo para que a dimensão política seja minimizada. Assim é que cursos e oficinas de CNV são oferecidos como forma de aumentar a produtividade em empresas e "estabelecer relacionamentos mais eficazes no trabalho" (ROSENBERG, 2006, p. 28).

Além disso, os objetos pelos quais circula por si sós provocam um estranhamento por parte de pesquisadores, pois o material escrito não segue os gêneros artigo acadêmico, dissertação ou tese; os livros estão, normalmente, dispostos junto à seção de autoajuda das livrarias, e as palavras são compostas por letras grandes e espaçadas, com uso de quadros explicativos e enunciados destacados em boxes a cada página. Analisando mais de perto os dois livros de Rosenberg que estamos tomando como base, é comum o uso de poemas, frases destacadas de outros autores, citações de memória (sem referências completas), menção a insights pessoais (que não são parte de pesquisa acadêmica), menção a princípios espirituais e também algum desdém por certa "ciência".

Tais motivos já seriam suficientes para levar a Linguística a rechaçar a CNV como uma proposta pouco séria. Afinal, o que dizer sobre uma área que não se pretende de pesquisa acadêmica, que figura nas livrarias junto a manuais de autoajuda, que circula como apolítica e espiritualista como a CNV?

Talvez, neste ponto, os leitores mais acadêmicos

\footnotetext{
12 Marcelo Knobel, reitor da Universidade Estadual de Campinas, fez referência a este fato na abertura do / Simpósio Unicamp e Direitos Humanos: Pesquisas e Ações, realizado em outubro de 2018. Knobel confessou que se sentia constrangido por, com mais de 50 anos de existência, a Unicamp estar realizando um evento deste tipo pela primeira vez e ter apenas há pouco mais de um ano (na época) um órgão institucionalizado para o tema (referindo-se ao então Comitê Gestor do Pacto Universitário pela promoção do respeito à diversidade, da Cultura de Paz e dos Direitos Humanos, hoje Diretoria Executiva de Direitos Humanos).
} 
possam estar pensando "por que estamos mesmo perdendo tempo com mais esse 'modismo-caçaníqueis-esotérico-neoliberal'"? A eles, respondo que a violência na linguagem é um problema, a CNV é uma proposta de solução que vem sendo adotada por milhares de pessoas e instituições do mundo. Os Estudos da Linguagem, como campo que se interessa pelas diferentes práticas linguageiras e, mais contemporaneamente, que quer ter algo a dizer sobre os discursos de intolerância e de ódio, tem que conhecer essa proposta. Passemos, então, a esmiuçá-la, seguindo os quatro componentes da CNV.

\subsection{0 "fato"}

Ao buscar não utilizar uma "comunicação alienante da vida" (ROSENBERG, 2006, p. 37), substituindo-a por uma comunicação compassiva, a CNV propõe que quatro elementos devem ser considerados e seguidos. O primeiro componente, o "fato", talvez seja o mais facilmente criticável pela Linguística. Esse componente é a postulação de que, para termos uma comunicação compassiva, precisamos nos ater a "observação" sem "avaliação". Rosenberg repete, nos dois livros que estamos analisando e em muitas de suas palestras, a frase do filósofo indiano Krishnamurti13: "observar sem avaliar é a forma mais elevada de inteligência humana".

O linguista identificará neste tipo de afirmação o desejo antigo de que a língua seja espelho do mundo, e a lamentação de que esse reflexo direto e claro seja conspurcado pelos falantes. Essa discussão já aparece em Frege, em 1892, quando ele diferencia "sinal", "sentido" e "referência" (FREGE, 1892), ou seja, o "sentido" não é a "referência" do mundo. É também presente no conceito básico de Saussure, fundador da Linguística moderna (que conhecemos através da obra póstuma Curso de Linguistica Geral, de 1916): o signo linguístico, "entidade psíquica de duas faces", "une não uma coisa e uma palavra, mas um conceito e uma imagem acústica". O significado, portanto, não é "a coisa do mundo", e sim um "conceito psíquico" (SAUSSURE, 1916, p. 80).
Temos, então, que considerar que, embora proponha uma nova forma de comunicação, a CNV não discute - ao menos não com bases linguísticas - o que seja língua ou linguagem. Parece adotar a concepção de comunicação de Jakobson (1963), em que há um "emissor", um "receptor", uma "mensagem" a ser transmitida sobre um "referente", um "canal", um "código" e possiveis "ruidos" que atrapalhem a clareza do processo. Retomamos aqui a clássica crítica da Análise do Discurso Francesa a essa concepção, a partir de um de seus principais textos fundadores, "Análise automática do discurso" (PÊCHEUX, 1969). Neste texto, partindo do esquema comunicacional de Jakobson, Pêcheux propõe que, em lugar de "emissor" e "receptor", sejam colocados "A" e "B", que representam lugares determinados na estrutura de uma formação social. Em lugar de "mensagem", seja colocado "discurso". Em lugar de "referente", seja colocado um objeto imaginário, o "ponto de vista do sujeito".

A partir desse deslocamento proposto pela Análise do Discurso, seria impossivel falar em "observar sem avaliar", ou ater-se ao "fato", como propõe a CNV. Afinal, os enunciados são "integralmente linguísticos e integralmente históricos" (MAINGUENEAU, 1984, p. 16) e não existe exterior para a ideologia, sempre falamos a partir de um lugar ideológico (o "ponto de vista do sujeito", para Pêcheux (1969)). Os conceitos de "competência interdiscursiva" e seu derivado "simulacro", formulados por Maingueneau dentro do quadro da Análise do Discurso, são significativos a esse respeito. Para esse autor, os individuos sempre enunciam de algum lugar discursivo, e o discurso é uma "comunidade de crenças, práticas e enunciados em torno dos quais é possivel dizer 'nós'" (MAINGUENEAU, 1984, p. 122). Os desentendimentos não são, quase nunca, problemas de comunicação no sentido de "ruidos", são traduções em "simulacros".

Em uma aula introdutória sobre Análise do Discurso para professores da Rede Básica de Educação do Estado de São Paulo, após discutir os princípios da disciplina - aproximadamente do

13 Não há referência, nos livros de Rosenberg aqui analisados, a onde ou quando Krishnamurti teria dito ou escrito essa afirmação. Sigo a forma como a citação foi apresentada. 
modo como acabei de apresentar aqui neste artigo - propus que os participantes escolhessem uma palavra e com ela formassem dois enunciados em que ficasse claro que o sentido decorre dos posicionamentos discursivos, e que não há "fato nu e cru" (ou palavra nua e crua ${ }^{14}$ ). Entre outros, os pares de enunciados abaixo foram produzidos:

\section{Par 1:}

Dia 23 conseguiremos nossa liberdade, isto é, desarmaremos o pais e teremos mais segurança.

Dia 23 conseguiremos nossa liberdade, isto é, garantiremos nosso direito de escolha de possuirmos ou não uma arma de fogo.

Par 2:

A educação deve ter qualidade, isto é, ser capaz de atender as necessidades do mercado de trabalho.

A educação deve ter qualidade, isto é, respeitare promover o desenvolvimento de cada aprendiz. ${ }^{15}$

Os dois enunciadores do par 1 estão falando de "liberdade", expressando o que para eles é um "fato", mas que são duas expressões de pontos de vista diametralmente opostas. Para o primeiro enunciador, liberdade é estar em um país desarmado; já para o segundo, liberdade é poder possuir uma arma de fogo. Análise análoga pode ser feita para o par 2. Para os dois enunciadores, "a educação deve ter qualidade" ("isto" é um "fato"). No entanto, ao especificar o que seria este "isto", através de "isto é", o primeiro enunciador alinha a qualidade na educação às necessidades do mercado, e o segundo enunciador a associa ao respeito ao desenvolvimento de cada aprendiz. Exemplos como esses, corriqueiros nas interações linguageiras cotidianas e presentes em todos os corpora analisados por pesquisas em Análise do Discurso, parecem tornar impossivel a proposta da CNV de se ater aos "fatos".

Vejamos mais um exemplo, em que a noção de "simulacro", como tradução de um discurso pelo seu opositor, opera com força:

Figura 1 - "Como é o mundo/Como uma feminista enxerga o mundo"

\section{COMO É O MUNDO}

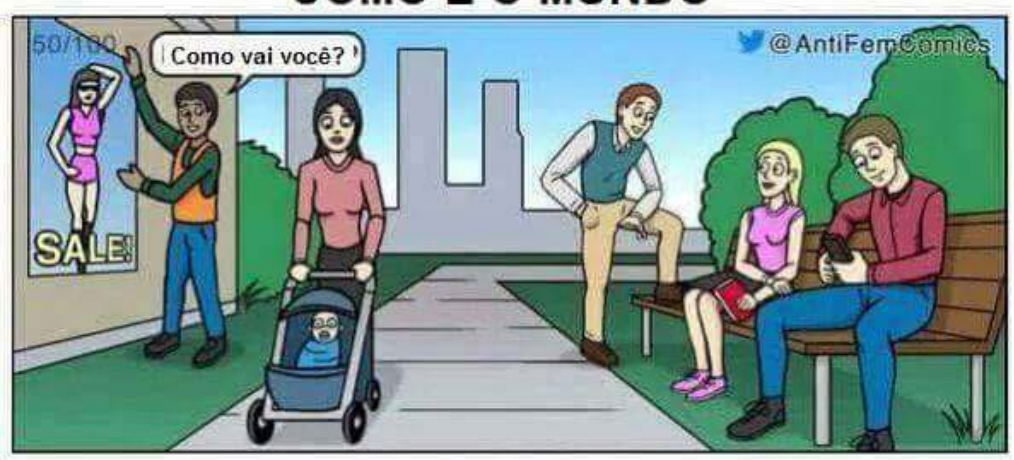

COMO UMA FEMINISTA ENXERGA O MUNDO

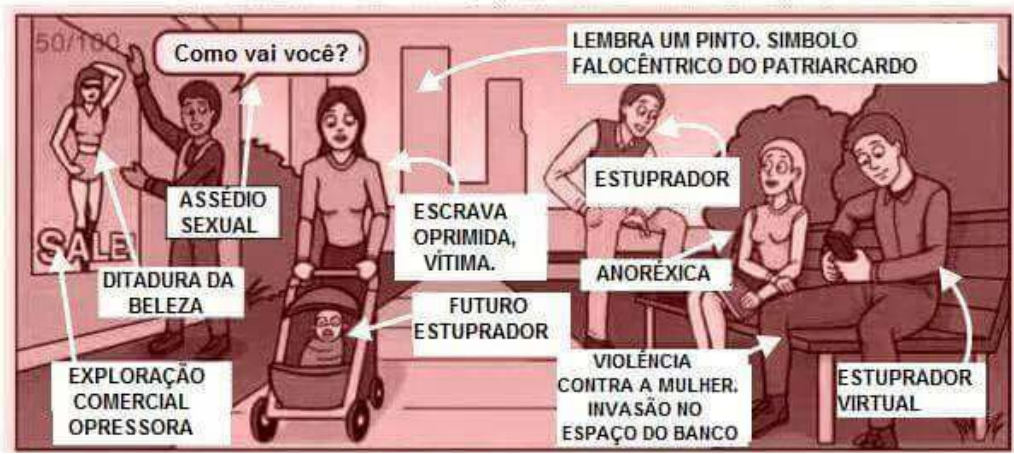

Fonte: Twitter de @antifemcomics. ${ }^{16}$

14 Conforme analisei em Motta (2009), a expressão "nu e cru" é muito interessante quando se pretende caracterizar uma linguagem clara, espelho da realidade (nua e crua). Seria a ausência de cultura, o estado "natural" (animal?) do ser humano, sem roupas e comendo sem cozinhar 15 Tratava-se do Programa Ler para Aprender, convênio da Secretaria Estadual de Educação de São Paulo com a Unicamp, do qual fui professora em 2006. O Par 1 evoca o referendo que ocorrera no ano anterior sobre o desarmamento no Brasil.

16 Conta suspensa. Acesso em: 2-3 mar. 2015. 
A charge, dividindo o espaço em dois (acima e abaixo), apresenta a mesma cena. Acima, o enunciador apresenta o que seria a visão neutra: "Como é o mundo". Nela, há pessoas interagindo em uma espécie de praça, ladeada por uma parede. Uma mulher caminha com um bebê no carrinho, um homem cola um cartaz publicitário na parede, um homem (olhando seu celular) e uma mulher estão sentados em um banco e um outro homem apoia uma das pernas no banco, parecendo interagir com a mulher sentada. Todos têm aparências tranquilas e/ ou estão sorrindo. Na porção inferior, a mesma cena recebe "legendas" a partir do simulacro do discurso feminista. Por que falar aqui em simulacro? Porque trata-se de um enunciador antifeminista (a conta de Twitter se chama, inclusive, "antifem") "traduzindo" em seus termos (em sua própria competência discursiva) o modo como entende o feminismo. Assim, um mundo de "delírio persecutório" é apresentado. As pessoas que estão, no mundo "real" (porção superior do quadro), interagindo normal e alegremente, na visão distorcida das "feministas" estão dentro de um ambiente extremamente desigual e inseguro para as mulheres, em que todos os homens são assediadores ou estupradores (até o bebê) e todas as mulheres são escravas oprimidas e vítimas do padrão de beleza eurocêntrico e gordofóbico.

O material é interessante, especialmente para os objetivos a que se propõe este artigo, pois a questão do "fato" e da "avaliação" é explicitamente nomeada, através das duas legendas que designam, respectivamente, as duas seções do quadro. Os pontos de análise possiveis são muitos; por uma questão de espaço, me restringirei a alguns. Para o discurso da charge, o homem colando o cartaz é um fato. Haver uma mulher magra, branca, com roupa e pose sensual para vender uma roupa no cartaz não é um fato. Haver uma mulher e dois homens sentados ou apoiados em um banco é um fato. A mulher estar com as pernas fechadas, ocupando o menor espaço que lhe é possivel, e os dois homens estarem com as pernas abertas, um deles com uma das mãos posicionada na região genital de seu corpo não é um fato.

A breve análise é suficiente para problematizar ${ }^{17}$ o que são "fatos" e o que são "avaliações". Supondo que a CNV se dispusesse a colocar o enunciador da charge para dialogar com uma feminista, o que seriam considerados "fatos"? Conto um exemplo pessoal: trabalhei esta charge com algumas turmas de alunos universitários. As reações dos alunos a ela dividiram-se, basicamente, em dois grupos. Duas ocorrências foram especialmente expressivas: em uma turma, um aluno bateu palmas e disse nunca ter visto algo tão verdadeiro em toda a sua vida. Em outra turma, uma aluna expressou ficar fisicamente nauseada após ver a charge.

\subsection{0 "sentimento"}

O segundo componente da CNVé o "sentimento". Após identificar o fato e circunscrevê-lo sem avaliações, a pessoa que queira comunicar-se sem violência precisa identificar quais são os sentimentos que aquele fato provoca em si mesma. A CNV afirma que temos grande dificuldade de identificar, isolar e nomear nossos sentimentos, que frequentemente são confundidos com pensamentos e julgamentos de nós mesmos e dos outros. Essa distinção é importante porque, para a CNV, o que os outros fazem ou o que acontece no mundo nunca é a causa para nossos sentimentos; é, no máximo, o estímulo. A causa sempre é alguma necessidade interna não satisfeita ("necessidade" é justamente o terceiro componente, que será desenvolvido na subseção seguinte deste artigo).

A respeito desse componente, por mais que haja esforços - mesmo que minoritários - para o tratamento das emoções e dos sentimentos pela Linguística, na CNV fala-se de um outro lugar: o que interessa é a aplicação no âmbito mais intimo, que cada um investigue o que se passa dentro de si e dentro do outro com quem está se relacionando. Nos termos utilizados nas duas obras que nos servem de análise para este artigo, perguntas primordiais seriam: "o que está vivo em mim?" "o que está vivo em você?" (ROSENBERG, 2019, p. 37); por isso esta abordagem também se autodenomina "a linguagem da vida". 
A maior contribuição que olhar através das lentes da Linguística pode dar para este componente é analisar as afirmações de base linguistica feitas pela CNV sobre o "sentimento". Aspectos semânticos do verbo "sentir" são apontados, alguns empregos são "autorizados" e outros criticados como parte de uma "comunicação alienante da vida", pois que não contribuem para a verdadeira expressão de sentimentos, e sim para uma confusão entre pensamentos, julgamentos e sentimentos, com consequente mascaramento dos sentimentos. Exporei esquematicamente o que a CNV recomenda a respeito do sentimento. Os quadros serão montados com fins organizacionais, para que eu possa me referir a seus elementos no momento das análises. Minhas interferências na montagem dos quadros serão as menores possiveis. No quadro 1, apresentarei os três critérios (seguidos de exemplos) que Rosenberg propõe para usos inadequados do verbo "sentir":

Quadro 1 - Usos inadequados do verbo "sentir" segundo a CNV

Quadro 1

Em geral, os sentimentos não estão sendo claramente expressos quando a palavra sentir é seguida por:

A. Termos como que, como, como se:

"Sinto que você deveria saber isso melhor do que ninguém."

"Sinto-me como um fracassado."

"Sinto como se estivesse vivendo com uma parede."

B. Vocábulo que seguido de pronomes como eu, ele, ela, eles, isso etc.:

"Sinto que eu tenho de estar constantemente disponivel."

"Sinto que isso é inútil."

C. Vocábulo que seguido de nomes ou palavras que se referem a pessoas:

"Sinto que Lúcia tem sido bastante responsável."

"Sinto que meu chefe está me manipulando."

Fonte: Elaborado a partir de ROSENBERG, 2006, p. 68-69.

No Quadro 2, há outro uso não recomendado:

Quadro 2 - Usos inadequados para expressão dos sentimentos segundo a CNV.

\section{Quadro 2}

Da mesma forma, é útil diferenciar palavras que descrevem o que pensamos que os outros estão fazendo à nossa volta de palavras que descrevem sentimentos reais. (...) na verdade, elas revelam mais sobre como achamos que os outros estão se comportando do que sobre o que realmente estamos sentindo:

A. "Sinto-me insignificante para as pessoas com quem trabalho."

A palavra insignificante descreve como acho que os outros estão me avaliando, e não um sentimento real, que, nessa situação, poderia ser "Sinto-me triste" ou "Sinto-me desestimulado".

B. "Sinto-me incompreendido."

Aqui, a palavra incompreendido indica minha avaliação do nivel de compreensão de uma outra pessoa, em vez de um sentimento real. Nessa situação, posso estar me sentindo ansioso, ou aborrecido, ou estar sentindo alguma outra emoção.

C. "Sinto-me ignorado."

Mais uma vez, isso é mais uma interpretação das ações dos outros do que uma descrição clara de como estou me sentindo. Sem dúvida, terá havido momentos em que pensamos estar sendo ignorados e nosso sentimento terá sido de alivio, porque queriamos ser deixados sozinhos. Da mesma forma, terá havido outros momentos em que nos sentimos magoados por estar sendo ignorados, porque queríamos participar. (elaborado a partir de ROSENBERG, 2006, p. 70-71)

Fonte: Elaborado a partir de Rosenberg (2006, p. 70-71). 
Tais "recomendações" são estranhas ao linguista, pois estamos aqui no terreno da prescrição, e não da descrição dos fatos de lingua ou de discurso. Ou seja, para o linguista, caberia anotar que o verbo "sentir" é utilizado de diferentes formas e com diferentes sentidos, mas não condenar uma forma ou um sentido em prol de outra ou outro. São estranhas também ao gramático normativo ou ao professor de língua, pois não se trata de uma prescrição que dita a forma mais polida, mais culta ou mais elegante de falar, e sim uma prescrição que tem por objetivo promover o encontro do enunciador com seus sentimentos. Superado o estranhamento e na hipótese de que se veja valor em fomentar trocas linguageiras mais construtivas e menos violentas, cabe prestar atenção ao que propõe a CNV e examinar o que a Linguística tem a dizer ${ }^{18}$.

Primeiramente, em relação ao Quadro 1, podemos questionar os critérios de divisão dos exemplos elencados por Rosenberg para se delimitarem as três situações linguísticas em que o uso do verbo "sentir" está a serviço da comunicação "alienante da vida" (ou "violenta"). Rosenberg separa as situações nos grupos A, B e $C$, sendo que, em $A$, o critério é a frase apresentar o verbo "sentir" seguido por "termos como que, como, como se". Assim, no critério A, os termos "que", "como" e "como se" são igualados, sem que haja explicação para tal. No entanto, as frases que apresentam "sinto" seguido por "que", como é o caso do primeiro exemplo do bloco A, encaixamse perfeitamente no grupo $B$. Inclusive, o primeiro exemplo de $A$ atende a todos os critérios do grupo B: "Vocábulo que seguido de pronomes". Ora, a frase é: "Sinto que você deveria saber isso melhor do que ninguém.", ou seja, nela temos o verbo "sentir", seguido por "que" e um pronome ("você"). Portanto, a primeira reformulação que seria necessária para proporcionar clareza de critérios seria o deslocamento do termo "que" do critério A para o critério $B$, e o consequente deslocamento do primeiro exemplo de A para o grupo B, ao qual ele, pela lógica, já pertence.

Continuando a análise, vemos que o critério $C$ é praticamente o mesmo critério $B$, apenas com a troca de "pronomes" por "nomes" ou "palavras que se referem a pessoas" (aliás, uma definição possivel para "pronomes"). Assim, proponho que se unifiquem os critérios B e C. Ficariamos com o seguinte quadro 1 reformulado:

Quadro 3 - Reformulação do Quadro 1

Quadro 1 - reformulado (mudanças em negrito):

A. Termos como [...] como, como se:

"Sinto-me como um fracassado."

"Sinto como se estivesse vivendo com uma parede."

B. Vocábulo que seguido de nomes próprios, pronomes (como eu, você, ele, ela, eles, isso etc.) ou outras palavras que se referem a pessoas (como meu chefe, o guarda, a professora etc.)

"Sinto que você deveria saber isso melhor do que ninguém."

"Sinto que eu tenho de estar constantemente disponivel."

"Sinto que isso é inútil."

"Sinto que Lúcia tem sido bastante responsável."

"Sinto que meu chefe está me manipulando."

Fonte: Elaboração própria (2020), a partir de Rosenberg (2006).

Em todos os usos desaconselhados para o verbo "sentir" do Quadro 1, o objeto direto do verbo "sentir" é uma oração subordinada (por isso inicia- se com as conjunções "como" ou "que"). Os usos aconselhados do verbo "sentir" são os em que ele tem como objeto direto um adjetivo: "triste",

18 Por não ser o único objetivo deste artigo, a análise deste ponto será feita apenas em língua portuguesa. Certamente a análise teria de ser validada caso se tratasse de outras línguas (por exemplo, para o francês, já haveria no mínimo dois verbos a se considerar: "sentir" e "ressentir"). 
"desestimulado", "ansioso", "aborrecido", "aliviado", "magoado" (segundo o Quadro 2). Mas, mesmo nos usos aconselhados, os adjetivos que "revelam mais sobre como achamos que os outros estão se comportando do que sobre o que realmente estamos sentindo" (ROSENBERG, 2006, p. 70) também são desaconselhados. Nesse último caso, Rosenberg elenca diversos exemplos, como "ameaçado", "atacado", "desapontado", "rejeitado", "sobrecarregado" (2006, p. 71). No exercício que propomos neste artigo, de buscar um maior rigor em coerência para a CNV, cabe perguntar por que em "pressionado" temos um julgamento sobre o outro, mas em "abandonado" (2006, p. 74) ou "encorajado" (2006, p. 72) temos a expressão real de sentimentos. Talvez melhor que se apegar a uma lista de palavras, seja a orientação para o autoexame de quem deseja se conectar com seus sentimentos, a partir do cuidado de que não esteja situando no comportamento do outro o que acha que é um sentimento seu. Por exemplo, uma pessoa pode se sentir "pressionada" por si mesma, isso é mesmo um comportamento bastante comum na contemporaneidade, conforme indica Han (2017) com seu conceito de "sujeito do desempenho".

Voltando à análise do Quadro 1, em português, o verbo "sentir" tem, como um de seus principais significados, uma formulação como "perceber pelos meios do sentido" ou "experimentar sensação física ou moral". No entanto, além desse seu sentido mais primário, o verbo "sentir" é um dos lexemas mais utilizados em língua portuguesa para expressão da evidencialidade, ou seja, expressão da fonte de informação de um enunciado. Linguistas observam que, em muitas línguas, a evidencialidade é marcada por itens gramaticais (afixos) que provêm de verbos que expressam percepção por meio dos sentidos, como "ver", "ouvir", "sentir". Em português, não houve gramaticalização desses termos, e a evidencialidade é marcada por itens lexicais, em muitos casos pelos verbos que expressam percepção.

Vendrame-Ferrari (2012a; 2012b) analisa que "sentir" pode indicar evidencialidade inferida, nos casos em que a fonte da informação é creditada a "uma conjectura baseada em evidências internas ao falante" (VENDRAME-FERRARI, 2012a, p. 108).
Ela dá, entre outros, o seguinte exemplo (2012a, p. 106, grifo da autora):

Senti que a briga estava mais violenta, pois a garota começou a gritar e o rapaz a bronquear com ela. O carro estava balançando. (http://bardoescritor.net/maobranca/contos/tatuagem.htm)

Pelo breve estudo apresentado, é possivel concluir que os usos do verbo "sentir" apontados no Quadro 1 por Rosenberg como inadequados para a "expressão real de sentimentos" são os usos de "sentir" como marcador de evidencialidade inferida. É interessante observar que Rosenberg. mesmo sem a teoria linguística subjacente, tenha indicado que, nesses usos, o verbo "sentir" não expressa "sentimentos", mas "pensamentos": "uma conjectura", nas palavras de Vendrame-Ferrari.

\subsection{A "necessidade"}

O terceiro componente da CNV são as necessidades, a "causa" ou "raiz" dos sentimentos. Rosenberg (2006, 2019) parte do principio de que todos os seres humanos têm as mesmas necessidades básicas, e acredita que "cada um de nós é responsável por seus próprios pensamentos, sentimentos ou atos" (ROSENBERG, 2006, p. 42), que são sempre motivados por nossas necessidades, das quais normalmente não nos damos conta, "pois aprendemos desde cedo a isolar o que se passa dentro de nós" (2006, p. 47). Em CNV, necessidades também são chamadas valores, e algumas delas são: de autonomia, de celebração, de integridade, de interdependência, de lazer, de comunhão espiritual, necessidades físicas e os desdobramentos de todas essas.

Neste terceiro componente, chama a atenção um movimento duplo, mas em sentidos opostos, da CNV, que contribui para uma oscilação quanto à clareza na delimitação de seus objetivos. Refirome ao papel do absoluto e do relativo com relação a valores, uma questão mal resolvida nesta abordagem. Neste terceiro componente, procuro situar a CNV frente a outros discursos, com os quais se coloca em posição de aliança ou conflito (nem sempre aparentes). Para tal, articularei a CNV aos discursos relacionados aos direitos humanos, ligação pertinente e importante 
e que está silenciada em Rosenberg (2006; 2019).

Palma et al (2018) identificam

[...] dois campos principais de significados atribuidos historicamente aos direitos humanos: uma linha de compreensão moderna do direito natural, ancorada principalmente no pensamento de base liberal, e que encontra fundamento nos principios da igualdade e da universalização ('somos todos iguais, o direito nos reconhece como iguais'); outra, na perspectiva pós-moderna, em que se verifica a um reforço à aceitação das diferenças e dos direitos culturais e das minorias ('cada indivíduo tem o direito de ser diferente'). A primeira acepção relaciona-se aos termos da cultura da paz e da internacionalização; a segunda estaria mais diretamente ligada à noção de diversidade (PALMA et al., 2018, p. 711).

A Declaração Universal dos Direitos Humanos (DUDH) (ONU, 1948) se situa na primeira linha identificada por Palma et al., da universalização dos principios, dos direitos e dos valores. Uma crítica comum à DUDH é a de que ela circula como a-histórica, seus enunciados são generalizantes e não consideram as especificidades culturais: tratase do "Homem" em uma espécie de "estado natural". A partir dessa crítica, seria necessário encarar os direitos humanos de uma forma "mais voltada para a ação do que fundada em conceitos genéricos e estáveis, ou posturas contemplativas" (PALMA et al., 2018, p. 701). Crítica semelhante é feita por Salgado e Silva (2014) a respeito da necessidade de vermos a heterogeneidade de discursos, porvezes opostos, de que podem fazer parte expressões aparentemente consensuais como "cultura de paz".

Alguns enunciados da CNV podem ser identificados com a postura abstrata, genérica e universal que caracteriza a primeira linha identificada ao campo dos direitos humanos, ainda mais porque, na CNV, há explicitamente o componente espiritual em jogo (o que contribui ainda mais para situá-la no âmbito do transcendente e universal). Apesar de não haver menção à filiação da abordagem a alguma religião em específico, nos dois livros de Rosenberg há assunção explícita dos "fundamentos espirituais dlo] trabalho" (ROSENBERG, 2006, p. 6), e a definição da CNV como "a integração de uma certa espiritualidade com ferramentas concretas que possibilitam a manifestação dessa espiritualidade no nosso dia-a-dia, em nossos relacionamentos e atividades politicas" (ROSENBERG, 2019, p. 26). Assim, lemos que o estado compassivo "provém da energia divina da qual somos constituidos, nossa energia natural de servir à vida" (ROSENBERG, 2019, p. 26).

No entanto, talvez por horror à palavra "moral" ou por horror a soar "moralista" ou "moralizante", 19 Rosenberg não menciona os direitos humanos nem assume que haja, para a CNV, "certo/errado", "bom/mau", "egoísta/altruísta" (ROSENBERG, 2019, p. 29). Sendo assim, por um lado há, na CNV, um código de ética bastante delimitado, baseado inclusive na dimensão espiritual, que define quais são os valores (necessidades) naturais e universais do ser humano. Sem rodeios, são nomeados "igualdade", "honestidade", "liberdade", "paz", "nãoviolência", "compaixão", "empatia", "acolhimento", "gentileza". Mas, por outro lado, é afirmado que fazemos julgamentos moralizadores, que devem ser evitados - por serem violentos - todas as vezes em que afirmamos algo como "a violência é ruim" (ROSENBERG, 2006, p. 39).

Fica claro o objetivo da CNV de não rotular pessoas como "boas", "más", "terroristas", "libertárias", "burras", "inteligentes", "preguiçosas". Esse principio é reforçado em diversas passagens dos dois livros, inclusive é justificado por uma menção ao semanticista Wendell Johnson, ${ }^{20}$ único linguista mencionado por Rosenberg, de quem há uma longa e curiosa citação, que reproduzo:

\footnotetext{
19 Yves de La Taille (2006) analisa a dificuldade com a palavra "moral", segundo ele, proveniente da contracultura dos anos 1960. autor cita, a esse respeito, o lema de maio de 1968: "É proibido proibir". Ele destaca o sentido pejorativo de "moralista", que parece ser exatamente o que circula nas duas obras analisadas no presente artigo, e do qual Rosenberg parece querer fugir: "alguém que interpreta, e portanto julga, a maioria das ações humanas por intermédio de critérios normativos, notadamente com uma clara vocação a normatizar condutas sexuais ou a elas associadas (jeito de se vestir, de falar etc.), é alguém rígido, com pouca vocação para a compreensão psicológica das ações, é alguém extremamente vigilante das condutas alheias, em geral mais do que em relação às próprias (dai a aproximação de sentido entre moralista e hipócrita)" (LA TAILLE, 2006, p. 27-28).

20 O trecho citado está no livro Living with change. Wendell Johnson ficou bastante conhecido por o que, posteriormente, foi chamado de o "estudo monstro", uma pesquisa de doutorado sobre gagueira que ele orientou, tendo como sujeitos crianças órfãs, hoje considerada uma das pesquisas mais antiéticas da história da ciência. Para além desse episódio, atuou de forma importante nas áreas de Psicologia, Fonoaudiologia e Linguistica.
} 
Nossa linguagem é um instrumento imperfeito, criado por homens antigos e ignorantes. É uma linguagem animista, que nos convida a falar a respeito de estabilidades e constâncias, de semelhanças, normalidades e tipos, de transformações mágicas, curas rápidas, problemas simples e soluções definitivas. No entanto, o mundo que tentamos simbolizar com essa linguagem é um mundo de processos, mudanças, diferenças, dimensões, funções, relações, crescimentos, interações, desenvolvimento, aprendizado, abordagem, complexidade. E o desencontro entre esse nosso mundo sempre em mutação e as formas relativamente estáticas de nossa linguagem é parte de nosso problema (JOHNSON, 1972 apud ROSENBERG, 2006, p. 50-51).

A citação de Wendell Johnson serve como argumento de autoridade (de um semanticista) de que a linguagem que utilizamos seria reflexo de um mundo estático, que já não corresponde ao mundo atual e, por isso, leva a cristalizações de julgamentos. A CNV, ao contrário, se pretende uma linguagem dinâmica, pertinente em um mundo em que as transformações são possiveis. O ponto que levanto aqui é que há um sentido claro que é desejável para essas transformações de acordo com a CNV, mas esse sentido não é sempre assumido, por se evitar o que seria um "autoritarismo" de se considerar algumas ações e comportamentos como bons ou maus. Os reflexos dessa indefinição podem ser especialmente complicados nas aplicações de CNV em escolas, por exemplo. ${ }^{21}$

Considero, com Bobbio (2004, p. 16), que "o problema fundamental em relação aos direitos do homem, hoje, não é tanto o de justificá-los, mas o de protegê-los". É também o que defende Murcho, quando, ao diferenciar o respeito pela "diversidade cultural" - desejável - do "relativismo cultural" - indesejável - afirma que "o relativismo cultural é incompatível com a ideia de direitos humanos universais" (MURCHO, 2010, p. 45). No Brasil atual, em que os Direitos Humanos têm sido considerados por uma parcela da população (com endosso do governo federal), como uma pauta de esquerda, defendê-los torna-se indispensável.

Não se trata de negar que a DUDH seja um documento histórico, discursivo, marcado por suas condições de produção. Mas se trata de afirmar que ela é um horizonte do qual não podemos abrir mão, e que suas modificações devem ser sempre positivas, no sentido de mais humanismo, justiça e solidariedade, e não de menos. Para isso, é importante que ações que visam a paz, como a CNV, se posicionem de modo claramente favorável aos valores dos Direitos Humanos, e claramente contrário aos valores da violência.

\subsection{0 "pedido"}

O quarto e último componente da CNV é o "pedido". Após ter observado o fato sem julgamento, identificado o sentimento que aquele fato provoca em si, localizado a necessidade (atendida ou não atendida) que está na raiz desse sentimento, é hora de fazer o pedido, ou seja, expressar-se em "linguagem clara, positiva e de ações concretas" que revelem "o que realmente queremos" (ROSENBERG, 2006, p. 107).

Toda a análise feita para o primeiro componente, o "fato", é válida para o quarto. Novamente aqui entra em jogo o conceito de linguagem como espelho (no primeiro componente, espelho do mundo; aqui, espelho do pensamento). Rosenberg conta diversos exemplos de pedidos bem feitos, em que a "mensagem que enviamos" é a "mensagem que é recebida" (ROSENBERG, 2006, p. 113), e isso é capaz de transformar conflitos violentíssimos, como o racismo em escolas dos Estados Unidos em que ele trabalhou e a relação entre palestinos e judeus que ele também mediou.

Uma proposta bastante simples, mas de muito dificil execução, ${ }^{22}$ para se verificar se o pedido feito foi o pedido ouvido são as demandas por retorno, ou por simples repetição do que se ouviu o outro pedir. A esse respeito, a mediação de conflitos com utilização da CNV que tem sido feita como parte da justiça restaurativa apresenta muitos exemplos. Um deles, representativo, aconteceu em uma audiência de separação de um casal,

1 Por não ser o foco do presente artigo e requerer um bom desenvolvimento, deixo o tema para publicações futuras.

A maioria dos estudantes de CNV conta encontrar dificuldades em repetir o que alguém pediu ou ter seu pedido repetido por alguém, caso seja demandado a esse alguém. É curioso como uma tarefa aparentemente simples se torna muito complexa; uma explicação pode ser discursiva: a recusa em usar as palavras do outro. 
e a discussão era sobre a guarda dos filhos. A mulher disse: "Eu quero ficar com os filhos", então o juiz perguntou ao homem: "Você pode repetir o que ela disse?" e o homem respondeu: "Ela disse que eu não sou um bom pai" (Lélio Braga Calhau, informação verbal). ${ }^{23}$

Tal episódio, que se assemelha a outros relatados por Rosenberg, tem ligação estreita com o que Grice (1967) conceituou como implicaturas. Na clássica postulação de Grice, as implicaturas acontecem quando há a quebra de uma máxima conversacional, as quais são regidas pelo "princípio da cooperação", uma espécie de contrato tácito das trocas verbais. Grice postula que:

Podemos formular, então, um princípio muito geral que se esperaria (ceteris paribus) que os participantes observassem: Faça sua contribuição conversacional tal como é requerida, no momento em que ocorre, pelo propósito ou direção do intercâmbio conversacional em que você está engajado. Pode-se denominar este princípio de PRINCÍPIO DA COOPERAÇÃO (GRICE, 1967, p. 86, grifo do autor).

Para Grice, todas as vezes em que alguma máxima (da quantidade, qualidade, relação ou modo) não é cumprida - por exemplo quando é fornecido excesso de informações, ou quando o que é dito não pode ser comprovado, ou quando não há relação clara entre o que é dito e o tópico da conversa, ou quando algo é dito de maneira ambigua - são ativadas implicaturas conversacionais. As implicaturas são raciocinios de "correção de rota", que ocorrem quando os interlocutores acreditam que seu parceiro na troca verbal continua engajado no princípio da cooperação, portanto teve algum motivo não explícito para violar uma ou mais das máximas, ele "implicou" algo.

Ao falar sobre "fazer pedidos conscientemente", Rosenberg, através de exemplos, toca em questões pertinentes à teoria das implicaturas conversacionais. No trecho a seguir há três situações-modelos em que isso ocorre, de acordo com a CNV:

Às vezes, podemos ser capazes de formular um pedido claro sem colocá-lo em palavras. Suponha que você esteja na cozinha, e sua irmã, que está assistindo à televisão na sala, grite: "Estou com sede!" Nesse caso, talvez seja óbvio que ela está pedindo que você lhe traga um copo de água da cozinha.

Entretanto, em outras ocasiões, podemos expressar nosso desconforto e presumir erroneamente que o ouvinte compreendeu nosso pedido subjacente. Por exemplo, uma mulher poderia dizer ao marido: "Estou aborrecida porque você se esqueceu da manteiga e das cebolas que the pedi que comprasse para o jantar". Embora, para ela, possa parecer óbvio que ela está pedindo para ele voltar à loja, o marido pode pensar que suas palavras foram ditas apenas para ele sentir-se culpado.

É ainda mais comum que ao falar simplesmente não tenhamos consciência do que estamos pedindo quando falamos. Conversamos com os outros ou falamos a eles sem saber como estabelecer um diálogo em conjunto com eles. Jogamos palavras e usamos a presença dos outros como se fossem uma cesta de lixo (ROSENBERG, 2006, p. 110-111).

Analisando as três situações-modelos expostas por Rosenberg nos termos de Grice, temos que na primeira a implicatura conversacional aconteceu sem problemas entre os dois irmãos. O pedido da irmã, mesmo que violando a máxima da relação, foi compreendido pelo irmão.

No segundo caso, a implicatura pretendida pela esposa não foi compreendida pelo marido. Partindo talvez de um raciocínio como "ao deixar claro que estou chateada, ele vai realizar a ação em que falhou antes", a esposa viola a máxima da quantidade: ela fala menos do que seria requerido para que o marido compreendesse que ela está pedindo que ele volte ao mercado e faça as compras.

Na terceira situação, a própria pessoa não sabe qual o seu pedido quando fala o que fala. Por isso, muitas vezes se expressa através de ladainhas ou reclamações que o interlocutor não entende como estando dirigidas a ele. Ou seja, a implicatura, nestes casos, não está clara para nenhum dos participantes da interação verbal.

Para a CNV, é muito importante que os pedidos sejam feitos de forma direta e clara. Refletindo a partir de Grice, podemos dizer que se trata aqui de garantir que as implicaturas (quando houver) estejam sendo entendidas do mesmo modo por todos os participantes do diálogo.

\footnotetext{
23 Palestra do Promotor de Justiça do Ministério Público do Estado de Minas Gerais Lélio Braga Calhau, na Mesa de abertura do II Encontro Nacional de Equipes de Ajuda. Unicamp, Campinas, SP, Brasil, 24 ago. 2018.
} 


\section{Considerações finais}

Ao fim do percurso proposto para este artigo, embora o realizado esteja longe de esgotar o assunto, é possivel concluir que olhar a CNV pelas lentes da Linguística é um exercício capaz de trazer mais rigor, coerência e profundidade para os componentes da CNV: "fato/observação", "sentimento", "necessidade" e "pedido".

O olhar da Análise do Discurso é especialmente importante para tornar mais complexo o conceito de lingua, linguagem e comunicação com que opera a CNV, contribuindo para que os embates sócio-históricos, que atravessam os enunciadores, sejam levados em conta pela abordagem. Sem esta visada, a CNV corre o risco - aliás, como vem ocorrendo em algumas situações - de propor técnicas "puras", que são empregadas para azeitar relações violentas. É também importante para posicionar a CNV frente a outros discursos que se situam no grande guarda-chuva dos Direitos Humanos, posicionamento que implica uma decisão acerca da relatividade ou universalidade de valores, discussão capital na contemporaneidade.

A Pragmática, com a teoria das implicaturas conversacionais, também lança uma luz importante para melhor compreensão do que a CNV pretende com a "clareza" do quarto componente, o "pedido".

As reflexões sintáticas e semânticas a respeito do segundo componente, o "sentimento", mostram que é possivel um olhar mais preciso para as afirmações da CNV a respeito do comportamento de palavras e expressões, o que pode levar a desenvolvimentos mais abrangentes e significativos.

Para a Linguística, e especialmente para os pesquisadores que, como eu, pretendem que a área se engaje mais no combate a todas as formas de intolerância e violência, a análise da CNV aproxima as pesquisas acadêmicas de uma possivel proposta de intervenção, que, saibam os linguistas ou não, já está em curso em escolas, tribunais e empresas. Este artigo conclui ser a CNV uma proposta interessante, em que vale a pena se aprofundar, apesar de suas lacunas teóricas.

\section{Referências}

ABRAMOVAY, Miriam; RUA, Maria das Graças. Violência nas Escolas. Brasília: UNESCO, 2002.

AMOSSY, Ruth. Apologia da polêmica. Tradução de Mônica Magalhães Cavalcante. São Paulo: Contexto, 2017.

BANKS-LEITE, Luci. Aspectos argumentativos e polifônicos da linguagem da criança em idade pré-escolar. Campinas. Tese (Doutorado em Linguistica) Instituto de Estudos da Linguagem, Unicamp, 1996.

BOBBIO, Norberto. A era dos direitos. Tradução de Carlos Nelson Coutinho. Rio de Janeiro: Elsevier, 2004.

EVENSEN, Lars Sigmund. A Linguística Aplicada a partir de um arcabouço com princípios caracterizadores de disciplinas e transdisciplinas. In: SIGNORINI, I. \& M. Cavalcanti (org.) Linguistica Aplicada e transdisciplinaridade. Campinas: Mercado de Letras, 1998. p. 81-98.

FAIRCLOUGH, Norman. Discourse and social change. Cambrigde: Polity Press, 1992.

FREGE, G. Sobre o sentido e a referência. Lógica e Filosofia da Linguagem. São Paulo: Cultrix/USP, 1978 [1892]. p. 59-86

GALTUNG, Johan. Violence, Peace and Peace Research. In: FERRARI; CABRAL (org.). Comunicação, Estudos para a paz e violência organizacional: uma perspectiva critica. Organicom, São Paulo, a. 15, n. 28, p. 33-56, 1. ${ }^{\circ}$ semestre/2018. https://doi. org/10.11606/issn.2238-2593.organicom.2018.150590

GANDHI, Mahatma. Non-violent resistance (Satyagraha). Nova lorque: Schocken Books, 1961 [1951].

GRICE, Herbert Paul. Lógica e conversação. Tradução de João Wanderley Geraldi. In: DASCAL, Marcelo (org.). Fundamentos metodológicos da linguística. Campinas: Instituto de Estudos da Linguagem, 1982 [1967]. p. 81-103. v. 4 - Pragmática.

HAN, Byung-Chul. Sociedade do cansaço. Tradução de Enio Paulo Giachini. Petrópolis: Vozes, 2017.

JAKOBSON, Roman. Linguistica e Poética. Linguistica e comunicação. São Paulo: Cultrix, 1974 [1963]. p. 118-162.

$\mathrm{KOCH}$, Ingedore. Argumentação e Linguagem. São Paulo: Cortez, 2000.

LA TAILLE, Yves de. Moral e ética: dimensões intelectuais e afetivas. São Paulo: Artmed, 2006.

MAINGUENEAU, Dominique. Unidades tópicas e não tópicas. Tradução de Maria Cecilia Pérez de Souza-e-Silva. Cenas da Enunciação. Organização de Sírio Possenti e Maria Cecilia Pérez de Souza-e-Silva. Curitiba: Criar, 2006. p. 9-24

MAINGUENEAU, Dominique. Aforização - enunciados sem texto? Organização de Sírio Possenti e Maria Cecília Pérez de Souza-e-Silva. Doze conceitos em análise do discurso. Tradução Ana Raquel Motta. São Paulo: Parábola, 2010. p. 9-24. 
MOTTA, Ana Raquel. Heterogeneidade e aforização: uma análise do discurso dos Racionais MCs. Tese (Doutorado em Linguística) - Instituto de Estudos da Linguagem. Unicamp, Campinas, 2009.

MURCHO, Desidério. Ética e Direitos Humanos. Cadernos da Escola do Legislativo, Belo Horizonte, v. 12, n. 19, p. 37-56, jul./dez. 2010.

ORGANIZAÇÃO DAS NAÇÕES UNIDAS. Declaração Universal dos Direitos Humanos. Paris: Assembleia Geral da ONU, 1948.

PALMA, Daniela et al. Produção de estórias e o gosto de afazer: exercícios de imaginação em escrita para a educação em direitos humanos. In: SILVA, Daniel Nascimento; PALMA, Daniela (org.). Dossiê temático Direitos humanos: perspectivas, mediações, práticas comunicativas. Trabalhos em Linguistica Aplicada, Campinas, n. 57.2,. p. 699-730, maio-ago. 2018. https://doi.org/10.1590/010318138651914365851

PAVEAU, Marie-Anne. Linguagem e moral: uma ética das virtudes discursivas. Tradução de Ivone Benedetti. Campinas: Editora da Unicamp, 2015

PÊCHEUX, Michel. Análise automática do discurso (AAD-69). In: GADET, Françoise; HAK, Tony (org.). Por uma análise automática do discurso. Tradução de Eni Pulcinelli Orlandi. Campinas: Editora da Unicamp, 1990

PEREIRA DE CASTRO, Maria Fausta. Aprendendo a Argumentar: um momento na construção da linguagem. 2. ed. rev. Campinas: Unicamp 1996

PERELMAN, Chaïm; OLBRECHTS-TYTECA, Lucie. Tratado da Argumentação - A nova retórica. Tradução de Maria Ermantina Galvão. São Paulo: Martins Fontes, 1996 [1958]

PINKER, Steven. The better angels of our nature: a history of violence and humanity. Londres: Penguin, 2011.

ROCHA, Janaina; DOMENICH, Mirella; CASSEANO, Patrícia. Hip Hop: a periferia grita. São Paulo: Fundação Perseu Abramo, 2001

ROSENBERG, Marshall. Comunicação não-violenta: técnicas para aprimorar relacionamentos pessoais e profissionais. Tradução de Mário Vilela. São Paulo: Ágora, 2006.

ROSENBERG, Marshall. A linguagem da paz em um mundo de conflitos: sua próxima fala mudará seu mundo. Tradução de Grace Patrícia Close Deckers. São Paulo: Palas Athena, 2019.

SALGADO, Luciana Salazar; SILVA, Helena Maria Boschi da. Gênese discursiva da fórmula 'cultura de paz'. Acta Scientiarum: language and culture, Maringá, v. 36, n. 2, p. 131-137, 2014. https://doi. org/10.4025/actascilangcult.v36i2.22567

SAUSSURE, Ferdinand de. Curso de Linguística Geral. Tradução de Antônio Chelini; José Paulo Paes: Izidoro Blikstein. São Paulo: Cultrix, 1970 [1916].

SILVA, José Carlos Gomes da. Rap na cidade de São Paulo: Música, etnicidade e experiência urbana. Campinas. Tese (Doutorado em Ciências Sociais) - Instituto de Filosofia e Ciências Humanas, Unicamp, 1998.
SILVA, Daniel Nascimento; PALMA, Daniela (org.). Dossiê temático Direitos humanos: perspectivas, mediações, práticas comunicativas. Trabalhos em Linguistica Aplicada. Campinas, n 57.2, maio-ago. 2018. https://doi.org/10.1590/010318138652964411831

SOUZA, Raul Alves de et al. Do silêncio à ajuda: a experiência brasileira de combate ao bullying pela implantação das equipes de ajuda. XIII EDUCERE - CONGRESSO NACIONAL DE EDUCAÇÃO. Anais... Curitiba: PUC-PR, 2018. p. 17125-17137.

VENDRAME-FERRARI, Valéria. Orações complexas com verbos de percepção como forma de expressão da evidencialidade. Estudos linguísticos, São Paulo, v. 41, n. 1, p. 101-115, jan.-abr. $2012 a$

VENDRAME-FERRARI, Valéria. Verbos de percepção em construções evidenciais de acordo com o modelo da gramática discursivo-funcional. Revista Linguística/Revista do Programa de Pós-Graduação em Linguística da Universidade Federal do Rio de Janeiro, Rio de Janeiro, v. 8, n. 1, p. 100-112, jun. 2012b.

\section{Ana Raquel Motta}

Doutora em Linguistica pela Universidade Estadual de Campinas (Unicamp, Campinas, SP, Brasil), pesquisadora de pós-doutorado no Departamento de Linguística Aplicada da Universidade Estadual de Campinas (Unicamp), Campinas, SP, Brasil, com bolsa PNPD/Capes.

\section{Endereço para correspondência}

Ana Raquel Motta

Universidade Estadual de Campinas

R. Sérgio Buarque de Holanda, 571

Cidade Universitária, 13083859

Campinas, SP, Brasil 